\title{
Renal disease and accidental falls: a review of published evidence
}

\author{
Pablo Jesús López-Soto ${ }^{1}$, Alfredo De Giorgi ${ }^{2,3}$, Elisa Senno ${ }^{2}$, Ruana Tiseo ${ }^{3}$, Annamaria Ferraresi ${ }^{4}$, Cinzia Canella ${ }^{4}$, \\ María Aurora Rodríguez-Borrego ${ }^{1}$, Roberto Manfredini ${ }^{2,3}$ and Fabio Fabbian ${ }^{2,3^{*}}$
}

\begin{abstract}
Background: The pathogenesis of falling is complex, and identification of risk factors may be essential for prevention. The relationship between renal disease and falls is unclear, and the goal of this study was to collect the available evidence and investigate the relationship between accidental falls and renal dysfunction.

Methods: Electronic searches were performed in the MEDLINE, Scopus, Ovid SP and Web of Science databases to identify the appropriate literature. The themes used were: falls (combined in the title/abstract fall or falls or falling or faller* or fallen or slip* or trip* or (MeSH) accidental falls) and renal insufficiency (chronic or renal insufficiency or kidney diseases combined in title/abstract renal disease* or kidney disease* or renal insufficiency or kidney insufficiency or kidney failure or renal failure or MeSH renal insufficiency, chronic or renal insufficiency or kidney diseases). The incidence, risk factors, complications, and characteristics of the falls were analyzed.

Results: Eight prospective cohorts including five cross-sectional studies, and one case-control study were identified. No randomized controlled studies were found. The incidence of falls in chronic kidney disease patients ranged between 1.18 and 1.60 fall/patient year. These were frequent in frail older adults on hemodialysis treatment. Falling relapses in the same group of patients caused serious consequences. Data on pre-end stage renal disease (ESRD) were scarce.

Conclusions: The risk of falling appears to be common in patients with renal dysfunction especially in older adults undergoing hemodialysis. On the other hand, we could not find any conclusive data on pre-ESRD patients.
\end{abstract}

Keywords: Aging, Chronic kidney disease, Frailty, Falls

\section{Background}

Chronic kidney disease (CKD) is a common condition with significant medical, social, and economic burdens. It is commonly associated with several comorbidities especially in older adults $[1,2]$. Cardiovascular and neurological diseases are the most important risk factors for falls [3-5], but CKD is also an intrinsic risk factor for falling [6].

An accidental fall is defined as "inadvertently coming to rest on the ground, floor or other lower level excluding intentional change in position to rest on the furniture, wall or other objects" [7]. The risk of falling increases with age, and one-third of people aged

\footnotetext{
*Correspondence: f.fabbian@ospfe.it

${ }^{2}$ Clinica Medica, Department of Medical Science, University of Ferrara, Ferrara, Italy

${ }^{3}$ Department of Medicine, Azienda Ospedaliero-Universitaria (AOU) of Ferrara, Ferrara, Italy

Full list of author information is available at the end of the article
}

$\geq 65$ years fall at least once per year [8]. In 2010, the cost of falls in the US was $\$ 30$ billion [9].

Although falls are the consequence of a complex interaction between multiple risk factors [3], the coexistence of factors such as polypharmacy, comorbidities and changes in volume status suggests that patients with different degrees of CKD are more likely to fall than the general population.

Therefore, the aim of this study was to synthesize published research about accidental falls evaluating patients with renal failure. Furthermore, the quality of the scientific evidence obtained was also analyzed.

\section{Methods \\ Design \\ A review of observational studies and randomized con- trolled trials provides a narrative synthesis and assessment}

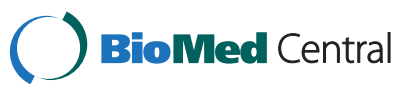

(c) 2015 López-Soto et al. Open Access This article is distributed under the terms of the Creative Commons Attribution 4.0 International License (http://creativecommons.org/licenses/by/4.0/), which permits unrestricted use, distribution, and reproduction in any medium, provided you give appropriate credit to the original author(s) and the source, provide a link to the Creative Commons license, and indicate if changes were made. The Creative Commons Public Domain Dedication waiver (http://creativecommons.org/publicdomain/zero/1.0/) applies to the data made available in this article, unless otherwise stated. 
of methodological quality of the included studies. The steps were searching, data extraction, assessing of quality, summarizing of finding and interpreting the results. This followed the Preferred Reporting Items for Systematic Reviews and Meta-Analyses (PRISMA) guideline [10, 11].

\section{Search methods}

Electronic searches of the published literature were performed in MEDLINE, Scopus, Ovid SP and Web of Science. Each database had customized searches due to the different vocabulary search terms and interfaces of the search in each database. The Cochrane Database was checked for reviews on the topic but there are, to our knowledge, no previous studies. The keywords used were the Medical Subject Heading (MeSH) terms of "accidental falls", "chronic", "renal insufficiency" and "kidney diseases". No age limits, restriction of language or date of publication were used.

The search strategy combined two search themes with the Boolean operator "and". The first theme was falls combined in the title/abstract fall or falls or falling or faller* or fallen or slip* or trip* or (MeSH) accidental falls. The second theme was renal insufficiency, chronic or renal insufficiency or kidney diseases combined in title/abstract renal disease* or kidney disease* or renal insufficiency or kidney insufficiency or kidney failure or renal failure or $\mathrm{MeSH}$ renal insufficiency, chronic or renal insufficiency or kidney diseases.

\section{Inclusion and exclusion criteria}

We included all studies with following criteria: (i) observational studies (cross-sectional, case-control, and cohort studies) or randomized controlled studies; (ii) studies including CKD adults and older adults (both pre-end-stage renal disease (ESRD) and ESRD); (iii) studies analyzing CKD patients with an increased propensity to fall.

We excluded: (i) root cause analysis studies or reviews or studies in dissertations and editorials; (ii) studies that were the end-point of bone evaluation.

\section{Search outcome}

The search terms and database searches were determined by two reviewers (E.S., P.J.L). They reached a consensus with respect to databases and search terms. These databases were chosen for their large coverage on the topic as well as the authors' previous experience with these databases. Between 20/10/2014 and 27/10/2014, each reviewer independently performed the electronic searches finding the same results in each database with the terms described above. They found a total of 13745 records.

According to the Moher et al. [11] recommendations, all details of the search process are shown in a PRISMA flow chart (Fig. 1). Researchers independently reviewed titles and abstract, and selected articles addressing the relationship between falls and CKD patients. They removed duplicate articles. At this step, 29 relevant titles were selected. On the second step, after reading the full article, we selected 14 articles that met with the a priori established inclusion and exclusion criteria. Disagreements in selected articles were resolved by discussion and consensus. Moreover, further relevant articles were added from the reference list of the primary articles.

\section{Quality appraisal of the publication}

The methodological quality of the articles was assessed by the same researchers who performed the search (E.S., P.J.L.). We assessed the articles using the Strengthening the Reporting of Observational studies in epidemiology (STROBE) checklist because there is no accepted gold standard for evaluating the methodological quality of selected articles (Version 4 published in October/November 2007 [12]). We did not intend to use this tool to determine methodological quality, but merely to use this checklist with 22 recommendations for the design of all selected studies (cross-sectional, case-control, and cohort studies) (Additional file 1).

In addition, to assess the quality of the same studies, we also applied the GRADE (Grading of Recommendations Assessment, Development and Evaluation) approach to address the following five domains: type of evidence, quality, consistency, directness and effect size [13].

\section{Data abstraction}

Data were extracted from each study according to the events of fall, main outcomes, fall risk factors, and methodology $[14,15]$ as well as the setting and sample (Table 1) and their characteristics (age, sex, and cause of renal disease) (Tables 2, 3 and 4).

\section{Synthesis}

There were 14 studies that met the inclusion criteria. We used a narrative approach due to the heterogeneity of the selected studies regarding methodology and difference in their designs and outcomes [15].

\section{Results}

The 14 relevant studies were all observational even if there were methodological differences. Eight of the fourteen studies had a prospective cohort design, five were cross-sectional and one was a case-control. No randomized controlled studies were found.

\section{Prospective cohort studies}

Four of the eight prospective studies were performed in Europe [16-19], while the other four were in North America (two in Canada $[20,21]$ and two in the USA $[22,23]$. All studies were performed in hemodialysis (HD) units. The population of the relevant prospective 


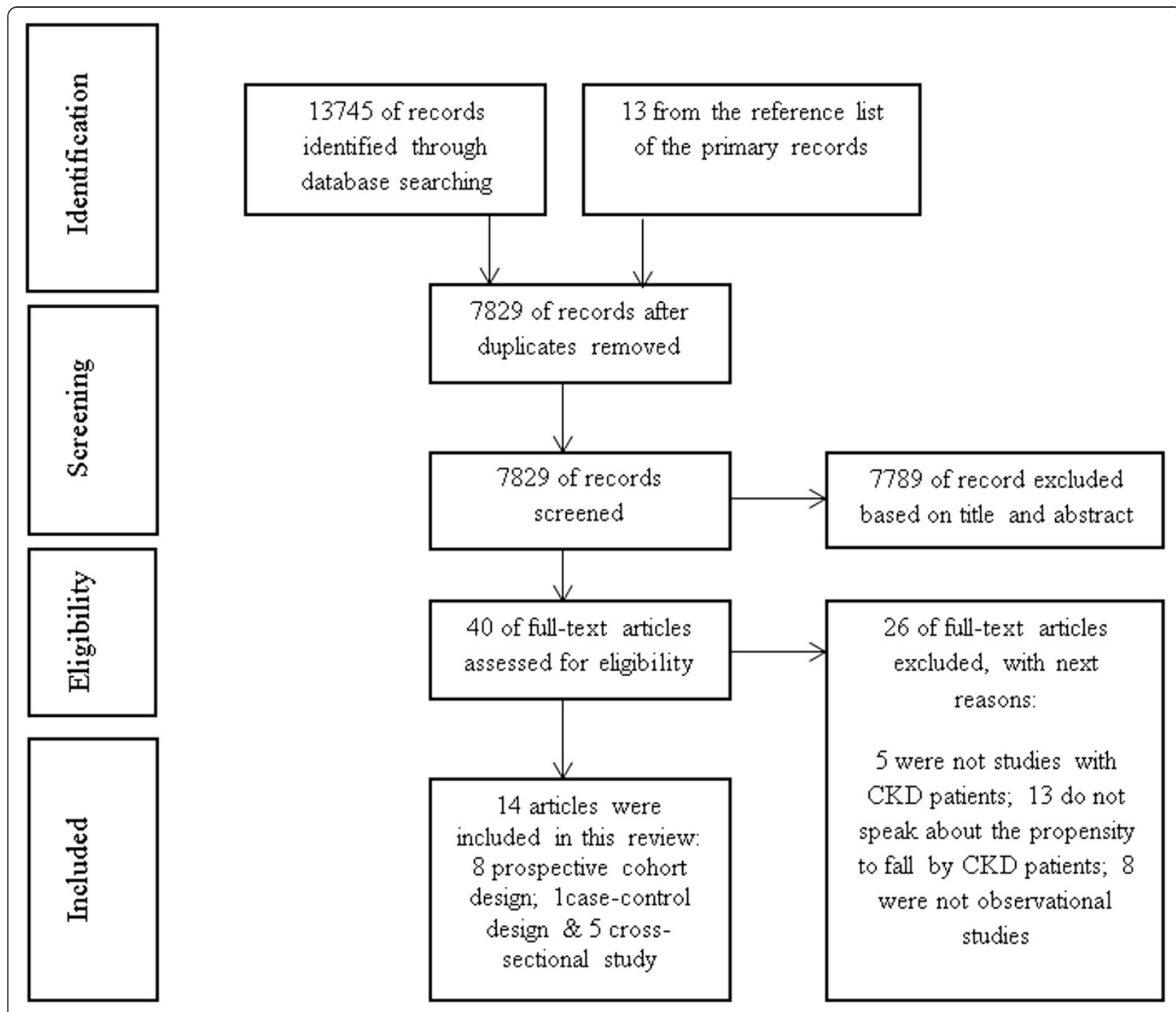

Fig. 1 PRISMA flow diagram of the screening process

studies varied between 76 [24] and 1385 subjects [19] with a total sample of 2357 patients. The mean age ranged between 58 [17] to 75.6 [19] years, however we identified subgroups with lower mean ages (47.1 years in patients under 65) [22] and higher mean age (75.8 years in patients over 65) [16].

\section{Incidence}

Five $[16-18,20,22]$ studies provided data on the incidence of falls. Roberts et al. [17] reported an incidence of 1.76 falls/patient year in subjects over 65 and of 0.13 falls/patient year in younger ones. Abdel-Rahman et al. [22] found an incidence of 1.54 falls/patient year in subjects over 65. Cook et al. [20] reported an incidence of 1.60 falls/patient year, but when one individual with 48 falls was excluded, the incidence was reduced to 1.36 . Only three articles reported data on the incidence of severe falls [16, 18, 22]. Desmet et al. [16] found an incidence of 0.37 falls/patient year for events requiring medical care, while Rossier et al. [18] and Cook et al. [20] described incidences of 0.22 and 0.20 falls/patient year, respectively.

\section{Risk factors}

Five [18-20, 22, 23] of the relevant prospective studies identified several risk factors for falls. Age over 65 years was a risk factor in three studies [16-18]. Gender was evaluated in three studies [20, 22, 23], but the results were conflicting. The relationship between falling and male gender was reported by Cook et al. [20], whilst Abdel-Rahman et al. [22] and McAdams-DeMarco et al. [23] demonstrated the risk for falling was higher in female patients. Other fall risk factors included a history of falls $[18,20]$, depression and therapy with 
Table 1 Parameters summarizing the main studies dealing with falls in renal dysfunction patients. Author, number of patients and events, setting, study design, risk factors and main outcomes are reported

\begin{tabular}{|c|c|c|c|c|c|}
\hline Author (year) & Sample (events) & Country \& setting & Type of study (study period) & Fall risk factors main outcomes & Checklist (Reporting) \\
\hline \multirow[t]{2}{*}{ Roberts (2003) } & 47 patients & UK & Cross-sectional study & \multirow{2}{*}{$\begin{array}{l}\text { There were significantly more } \\
\text { patients reporting falls and/or } \\
\text { syncope in elderly patients who had } \\
\text { post-dialysis orthostatic hypotension. }\end{array}$} & \multirow[t]{2}{*}{15} \\
\hline & (13) & 1 Hospital HD unit & (12 months) & & \\
\hline \multirow[t]{2}{*}{ Cook (2005) } & 135 patients & Canada & Cross-sectional study & \multirow{2}{*}{$\begin{array}{l}\text { There was no significant difference } \\
\text { in the incidence of falls among } \\
\text { "young-old" and "old-old" group in } \\
\text { either gender. }\end{array}$} & \multirow[t]{2}{*}{14} \\
\hline & (37) & 2 Outpatient HD unit & (12 months) & & \\
\hline \multirow[t]{2}{*}{ Desmet (2005) } & 308 patients & Belgium & Prospective cohort study & \multirow{2}{*}{$\begin{array}{l}\text { Older age, diabetes, failed walking } \\
\text { test, intake of an antidepressant and } \\
\text { high number of oral prescribed } \\
\text { drugs were identified as } \\
\text { independent predictors of falling }\end{array}$} & \multirow[t]{2}{*}{18} \\
\hline & (56) & 7 In-center HD units & (8 weeks) & & \\
\hline \multirow[t]{2}{*}{ Cook (2006) } & 169 patients & Canada & Prospective cohort study & \multirow{2}{*}{$\begin{array}{l}\text { Male gender, a history falls, low } \\
\text { mean pre-dialysis SBP, and higher } \\
\text { comorbidity were important risk } \\
\text { factors for falls }\end{array}$} & \multirow[t]{2}{*}{22} \\
\hline & $\begin{array}{l}\text { (305 falls over a median of } \\
468 \text { days) }\end{array}$ & 1 Outpatient HD unit & (12 months) & & \\
\hline \multirow[t]{2}{*}{ Angalakuditi (2007) } & 635 cases \& 1270 controls & USA & $\begin{array}{l}\text { Retrospective case-control } \\
\text { study }\end{array}$ & \multirow{2}{*}{$\begin{array}{l}\text { Increased likelihood of experiencing an } \\
\text { in-hospital fall occurred with dementia, } \\
\text { pneumonia, gastrointestinal disease } \\
\text { and diabetes, as well as taking } \\
\text { antidepressants and anticonvulsants. }\end{array}$} & \multirow[t]{2}{*}{21} \\
\hline & $\begin{array}{l}\text { (Falls determine the cases: } \\
635 \text { cases) }\end{array}$ & $\begin{array}{l}1 \text { University medical } \\
\text { center }\end{array}$ & (5 years \& 6 months) & & \\
\hline \multirow[t]{2}{*}{ Roberts (2007) } & 78 patients & UK & Prospective cohort study & \multirow{2}{*}{$\begin{array}{l}\text { Older patients fell more than } \\
\text { younger patients. There was no } \\
\text { relationship between incidence of } \\
\text { falls and the routine blood pressures } \\
\text { nor with hemoglobin concentration } \\
\text { or number of medications. }\end{array}$} & \multirow[t]{2}{*}{8} \\
\hline & (14) & 1 Hospital HD unit & (6 months) & & \\
\hline \multirow[t]{2}{*}{ Li (2008) } & 162 patients & Canada & Prospective cohort study & \multirow{2}{*}{$\begin{array}{l}\text { Falls were associated with double } \\
\text { risk of death. Risk of death increased } \\
\text { with } 1 \text {-year in dialysis or } 1 \text {-year in } \\
\text { age or with changes in hemoglobin, } \\
\text { serum albumin and the calcium- } \\
\text { phosphate product }\end{array}$} & \multirow[t]{2}{*}{18} \\
\hline & (305) & 1 Outpatient HD unit & (12 months) & & \\
\hline \multirow[t]{2}{*}{ Boudville (2010) } & $\begin{array}{l}25 \text { patients ( } 9 \text { with } 25 \mathrm{OHD} \\
\leq 50 \mathrm{nmol} / / ; 16 \text { with } 25 \\
\mathrm{OHD}>50 \mathrm{nmol} / \mathrm{l}\end{array}$ & Australia & Cross-sectional study & \multirow{2}{*}{$\begin{array}{l}\text { Suboptimal levels of } 25 \mathrm{OHD} \text { may } \\
\text { contribute to an increased risk of } \\
\text { falls. Although, not significant, there } \\
\text { were more falls in patients with } \\
\text { suboptimal levels of } 25 \mathrm{OHD} \text {. }\end{array}$} & \multirow[t]{2}{*}{20} \\
\hline & $\begin{array}{l}\text { Not determine incidence } \\
\text { of falls }\end{array}$ & 1 Outpatient HD unit & (No data) & & \\
\hline \multirow[t]{2}{*}{ Abdel-Rahman (2011) } & 76 patients & USA & Prospective cohort study & \multirow{2}{*}{$\begin{array}{l}\text { Female gender was a significant } \\
\text { predictor of falls. Compared to } \\
\text { 'non-fallers', 'fallers' had higher risk of } \\
\text { death, nursing home admission, and }\end{array}$} & \multirow[t]{2}{*}{18} \\
\hline & (20) & 2 Outpatient HD unit & (12 months) & & \\
\hline
\end{tabular}
468 days)

(Falls determine the cases: 78 patients

162 patients

Canada

(305)

25 patients ( 9 with $25 \mathrm{OHD}$

Not determine incidence

76 patients

2 Outpatient HD unit
(12 months) death, nursing home admission, and 
Table 1 Parameters summarizing the main studies dealing with falls in renal dysfunction patients. Author, number of patients and events, setting, study design, risk factors and main outcomes are reported (Continued)

\begin{tabular}{|c|c|c|c|c|c|}
\hline & & & & $\begin{array}{l}\text { increase in number and duration of } \\
\text { hospital. }\end{array}$ & \\
\hline \multirow[t]{2}{*}{ Rossier (2012) } & 84 patients & Switzerland & Prospective cohort study & \multirow{2}{*}{$\begin{array}{l}\text { POMA score along with age, a past } \\
\text { history of falls, malnutrition and } \\
\text { depression, were associated with } \\
\text { severe falls. }\end{array}$} & \multirow[t]{2}{*}{19} \\
\hline & (31 severe falls) & 1 Hospital HD unit & (3 years) & & \\
\hline \multirow[t]{2}{*}{ Galvão (2013) } & 64 patients & Brasil & Cross-sectional study & \multirow{2}{*}{$\begin{array}{l}\text { No correlation between PTH serum } \\
\text { levels and FES-I. Higher tendency to } \\
\text { fall among the patients who pre- } \\
\text { sented low calcitriol serum levels. } \\
\text { FES-I can be capable of discerning } \\
\text { falling from no-falling patients in HD }\end{array}$} & \multirow[t]{2}{*}{19} \\
\hline & $\begin{array}{l}\text { Not determine incidence of } \\
\text { falls }\end{array}$ & 1 Outpatient HD unit & (No data) & & \\
\hline \multirow[t]{2}{*}{ McAdams-DeMarco (2013) } & 95 patients & USA & Prospective cohort study & \multirow{2}{*}{$\begin{array}{l}\text { Fragility is an independent fall risk } \\
\text { factor adjusting for age, sex, race, } \\
\text { comorbidity, disability, number of } \\
\text { medications, marital status and } \\
\text { education. No difference between } \\
\text { younger and older adults was seen. }\end{array}$} & \multirow[t]{2}{*}{14} \\
\hline & (70) & 1 Outpatient HD unit & (15 months) & & \\
\hline \multirow[t]{2}{*}{ Kutner (2014) } & 762 patients & USA & Cross-sectional study & \multirow[b]{2}{*}{$\begin{array}{l}\text { Frail patients were over twice as } \\
\text { likely to report falls. Patients with } \\
\text { depression (CES-D }>18 \text { ) and/or } \\
\text { prescribed antidepressants were over } \\
80 \% \text { more likely to be faller than } \\
\text { were patients with no depression } \\
\text { (CES-D < 18) and no prescribed } \\
\text { antidepressants. }\end{array}$} & \multirow[t]{2}{*}{17} \\
\hline & (671) & 8 Outpatient HD unit & (12 months) & & \\
\hline \multirow[t]{2}{*}{ Rothenbacher (2014) } & 1385 patients & Germany & Prospective cohort study & \multirow{2}{*}{$\begin{array}{l}25 \text { OHD serum level were associated } \\
\text { with risk of first fall. Calcium levels } \\
\text { modified the effect. No association } \\
\text { existed between chronic kidney } \\
\text { disease and risk of first fall. }\end{array}$} & \multirow[t]{2}{*}{17} \\
\hline & $\begin{array}{l}\text { Not determine incidence of } \\
\text { falls }\end{array}$ & Community & (12 months) & & \\
\hline
\end{tabular}


Table 2 Age, sex, primary renal disease and comorbidity of patients enrolled in prospective studies

\begin{tabular}{|c|c|c|c|c|c|c|c|c|}
\hline & Mc-Adams [23] & Rossier (2012) & Rothenbacher [19] & Abdel-Rahman [23] & Li [21] & Roberts [17] & Cook [20] & Desmet [27] \\
\hline Age (mean $\pm S D$ ) years & $60.5 \pm 12.6$ & 69.5 & 75.6 & $62.4 \pm 6.1$ & $\begin{array}{l}74.7 \pm \\
6.1\end{array}$ & 58 & $74.7 \pm 6.1$ & 70.9 \\
\hline Male (\%) & 53.7 & 67 & 57.2 & 61.8 & 57 & 65.4 & 57 & N/A \\
\hline Female (\%) & 46.3 & 33 & 42.8 & 38.2 & 43 & 34.6 & 43 & N/A \\
\hline \multicolumn{9}{|l|}{ Renal diagnosis } \\
\hline Hypertension (\%) & N/A & 29.8 & N/A & N/A & & N/A & & N/A \\
\hline Diabetes mellitus (\%) & & 29.8 & & & 27 & & 27 & \\
\hline Glomerulonefritis (\%) & & 13.1 & & & 12 & & 12 & \\
\hline Hypertensive/renovascular (\%) & & N/A & & & 28 & & 28 & \\
\hline Other (\%) & & N/A & & & 28 & & 28 & \\
\hline Unknown (\%) & & N/A & & & 5 & & 5 & \\
\hline
\end{tabular}

$\mathrm{N} / \mathrm{A}=$ not applicable

antidepressants $[16,18]$, number of prescribed oral drugs [16], frailty [23], failed walking test [16], malnutrition [18], comorbidity [20], diabetes [16], and high school education [23].

Two studies estimated the proportion of patients remaining free of falls using Kaplan-Meier analysis $[18,19]$. Rossier et al. [18] calculated that after a mean follow-up of 465 days, $89.1 \%$ of patients $<65$ years were free of falls. Those between 65 and 75 were $57.2 \%$ free of falls, but only $30 \%$ in those over 75 . Rothenbacher et al. [19] estimated a risk of first fall that was associated with CKD but found no statistically significant relationship. Li et al. [21] found that a history of falls and serum albumin were independent risk factors for death associated with accidental fall.

\section{Complication of falls}

Data related to falls and complications of falls were reported in three studies [16, 20, 22]. Desmet et al. [16] found that the percentage of fall-related fractures was $3.9 \%$. Similar results were found by Cook et al. [20] (4\% of fall-related fractures), however in their study, six patients died and 26 were hospitalized as a direct result of the fall. Abdel-Rahman et al. [22], found 20 deaths (0.151 deaths per patient-year), 14 nursing home admissions and 219 hospitalizations over 2 years. They calculated higher rates for the risk of death (2.13-fold increase), risk of nursing (3.5-fold increase), and risk and number and duration of hospitalizations (2-fold increase) in 'fallers' than 'nonfallers'. They also found higher number of hospitalizations when comparing 'recurrent fallers' vs. 'non-fallers'.

Table 3 Age, sex, primary renal disease and comorbidity of patients enrolled in cross-sectional studies

\begin{tabular}{|c|c|c|c|c|c|}
\hline & Cook [26] & Boudville [27] & Roberts [24] & Galvao [28] & Kutner [25] \\
\hline Age (mean $\pm S D$ ) years & $74.9 \pm 6.2$ & $69.5 \pm 12.1$ & $78.2 \pm 5.3$ & $44.2 \pm 14.8$ & 57.1 \\
\hline Male (\%) & 61 & 80 & 49 & 73.4 & 59.2 \\
\hline Female (\%) & 39 & 20 & 51 & 26.6 & 40.8 \\
\hline \multicolumn{6}{|l|}{ Renal diagnosis } \\
\hline Diabetes mellitus (\%) & N/A & 24 & N/A & N/A & 36.9 \\
\hline Glomerulonefritis (\%) & N/A & 20 & 10 & N/A & N/A \\
\hline Hypertension (\%) & $\mathrm{N} / \mathrm{A}$ & 20 & 31 & N/A & 34.9 \\
\hline Polycystic kidney disease (\%) & N/A & 4 & 6 & N/A & N/A \\
\hline Obstructive nephropathy (\%) & N/A & N/A & 12 & N/A & N/A \\
\hline Nephrocalcinosis (\%) & N/A & N/A & 4 & N/A & N/A \\
\hline Chronic pyelonephritis (\%) & N/A & N/A & 2 & N/A & N/A \\
\hline Analgesic nephropathy (\%) & N/A & N/A & 2 & N/A & N/A \\
\hline Acute illness (\%) & N/A & N/A & 2 & N/A & N/A \\
\hline Other (\%) & N/A & 32 & N/A & N/A & N/A \\
\hline Unknown (\%) & N/A & $\mathrm{N} / \mathrm{A}$ & 25.5 & N/A & N/A \\
\hline
\end{tabular}

$\mathrm{N} / \mathrm{A}=$ not applicable 
Table 4 Age, sex and primary renal disease of patients enrolled in case-control study

\begin{tabular}{lll}
\hline Angalakuditi et al. [29] & Case & Control \\
\hline Age (mean \pm SD) & $68.5 \pm 15.3$ & $69.1 \pm 15.3$ \\
Sex & & \\
Male (\%) & 46.3 & N/A \\
Female (\%) & 53.7 & N/A \\
Renal diagnosis & N/A & N/A \\
\hline
\end{tabular}

$\mathrm{N} / \mathrm{A}=$ not applicable

\section{Characteristics of falls}

The location of falls was evaluated in two studies [16, 20]. Desmet et al. [16] reported a higher number of falls occurring at home (82\%) followed by public sites $(7 \%)$ and other $(9 \%)$ or unknown locations (2\%). Cook et al. [20] found different percentages between indoor (69\%) and outdoor falls (31\%). In the latter study, the authors evaluated the modality of the fall with walking (57\%) being the most common activity followed by standing from the seated position (31 \%) and trying to rise from a lying position (12\%). In both studies, the time of fall was analyzed. Desmet et al. [16] found a higher number of first falls within $22 \mathrm{~h}$ from a HD session; a similar frequency was seen with falls on dialysis and non-dialysis days [20]. However, this group showed a higher number after (73\%) than before $(27 \%)$ dialysis.

\section{Cross-sectional studies}

Five relevant cross-sectional studies were available [25-28]. All studied outpatient HD units. The five studies were conducted in different countries. The total population of the cross-sectional studies ranged from 25 to 762 subjects with a final total sample of 1033 patients of various characteristics. The mean age of the population ranged from 44.2 to 78.2 years.

\section{Average number of reported falls}

Two out of the five studies determined the number of falls $[24,26]$, and one reported the incidence of falls. Roberts et al. [17] reported 13 falls in a population of 47 patients; Cook et al. [20] calculated 37 falls over 12 months, and 21 falls in the prior 12 months in a population of $135 \mathrm{HD}$ patients. Meanwhile, 671 falls were reported by Kutner et al. [25] in 762 patients for an incidence of 0.88 falls/patient year. In this study, no differences were found between amputees and nonamputees.

\section{Risk factors}

Kutner et al. [25], reported that frailty was independently associated with higher risk of falls versus non-frail patients. Age increased the risk of fall, but elderly patients with good cognitive function scores had lower risks of falling. No significant risk factors for falls were found in the other four relevant cross-sectional studies in which age [26], sex [27], postural hypotension [24], levels of 25-hydroxyvitamin D (25-OH-D) [27] and other validated tools $[27,28]$ were considered as predictors of falls.

\section{Complications of fall}

Only Kutner et al. [25] calculated data about complications of falls-they described fractures in $11.2 \%$ of fallers (216 patients). The most common were upper or lower limb fractures followed by two hip fractures and one forehead injury; $71 \%$ of patients were hospitalized.

\section{Case-control design}

One relevant case-control study was selected [29]. This study evaluated the association between comorbidities and drug use with risk of the in-hospital falls in CKD patients. Falls were recorded in 635 out of 1905 . The majority of falls had no complications (77.3\% of cases), but abrasion was described in $5.4 \%$ of cases, pain in $2.8 \%$, laceration in $2.2 \%$, blood loss in $1.9 \%$ and fractures in eight $(1.3 \%)$. A significant percentage of subjects were discharged to nursing homes $(27.7 \%)$, rehabilitation units $(18.4 \%)$, short or intermediate skilled-care nursing facilities $(5.8 \%)$, and to other hospitals (2.0\%). Unfortunately, $7.7 \%$ of subjects died while hospitalized.

The majority of patients fell from the bed (39.6\%), and a $33 \%$ fell while ambulating. Other episodes include falls in the bathroom (16.0\%), from a chair $(9.1 \%)$, or falls that were not witnessed (found on the floor episodes $(9.1 \%))$. The time of fall in relation to length of stay determined that the majority of falls (57.6\%) occurred within the first week of hospitalization.

\section{Risk factors}

Comorbidities such as dementia, pneumonia, cardiac arrhythmias, gastrointestinal disease, and diabetes mellitus were risk factors for falling as well as the use of antidepressants and anticonvulsants.

\section{Methodological quality}

Using the STROBE checklist we assessed the quality of reporting of observational studies. This checklist is purely informative because it is not possible to determine the quality with this tool-only the recommendations are discussed. For this reason, the GRADE approach is used to assess the quality of the evidence. Due to the heterogeneity of the variables evaluated in different studies, we could only analyze age, frailty, previous falls and polypharmacy (Table 5).

On this basis, not all studies could be considered of acceptable quality. The quality of evidence for age and polypharmacy was very low. The data quality regarding 
Table 5 Quality of the risk factors for falling upon comparing fallers to non-fallers according the GRADE approach (based on our systematic review). Variables evaluated in different studies were heterogeneous, therefore only age, frailty, previous falls and polypharmacy could be analyzed

\begin{tabular}{|c|c|c|c|c|c|c|c|}
\hline Outcome & No. of studies & Design & No quality & Inconsistency & Indirectness & No effect size & Quality \\
\hline Age & 4 studies (700 subjects) & Prospective cohort studies & Very serious & Serious & Serious & Very serious & Very low \\
\hline Frailty & $\begin{array}{l}2 \text { studies define this specifically, } \\
\text { four others are related } \\
\text { ( } 857 \text { subjects) }\end{array}$ & $\begin{array}{l}\text { Prospective cohort } \\
\text { and cross sectional studies }\end{array}$ & No & Little or no & No & No & Low \\
\hline Previous falls & 3 studies (405 subjects) & Prospective cohort studies & Little or no & No & Little or no & No & Low \\
\hline Polypharmacy & $\begin{array}{l}3 \text { studies ( } 3598 \text { total subjects; } \\
1905 \text { in case and control study) }\end{array}$ & $\begin{array}{l}\text { Prospective cohort and } \\
\text { retrospective case-control } \\
\text { studies }\end{array}$ & Serious & Serious & Very serious & Serious & Very low \\
\hline
\end{tabular}

falls and previous falls was categorized into a higher level but was still relatively low.

\section{Discussion}

This review presents an overview of the available evidence dealing with the relationship between falling and CKD. Despite the important and comprehensive searches on this topic, we found only fourteen articles that met the established inclusion criteria.

The majority of studies were of moderate quality. In 8 out of 14, the authors designed a cohort investigation-only a few studies had a poor methodological design. We found that the incidence of falls in CKD patients ranged between 1.18 [16] and 1.60 [20] falls/patient year; falling was a result of relapsing in the same group of patients especially in older and frail patients.

Although the mean age of the selected studies ranged between 44 and 78 years, most data was related to older adults [30].

\section{Risk factors of falls}

Many different etiological factors might cause falling. Knowledge of these causes could facilitate the development of preventive measures.

Age is the main risk factor for falling in the general population [7]; up to half of people over 65 experience a fall every year [30]. Although not uniformly evaluated, age was significantly related to falls in CKD patients. Falls were more common in people over 65 years than younger subjects $[16,17]$. On the other hand, McAdams-DeMarco et al. [23] could not detect any difference in the frequency of falls in those under 65 and 65 and older (25.9\%, vs $29.3 \%$ ) over a median period of 6.7 month.

In this study after adjusting for age, sex, race, comorbidity, disability, number of medications, marital status, and education, frailty independently predicted a higher number of falls [23]. There were no sex-based differences in the risk of falling. Some studies have shown that women have an increased risk of falling [31], while others have shown similar data on men [32]. The higher prevalence of falls in women was associated with strength reduction or decrease in bone mineral density [20, 33, 34].

Frailty is an important risk factor for falls, however frailty has not been universally defined, and several conceptual models to define it have been used [35-37]. Frailty can be considered to be a syndrome of impaired homeostasis and resistance to stresses that leads to an individual's increased vulnerability and risk of adverse outcomes [38]. The Fried model is the most commonly used, and a person is considered to be frail when he/she develops three or more of the following symptoms: weight loss, exhaustion, loss of grip strength, decreased gait or low physical activity [36]. Only two studies [23, 25] reported a relationship between frailty and falling in CKD patients, and the association was strong. The lack of data regarding this relationship could be ascribed to the heterogeneity in the definitions used or to underestimation of the problem by nephrologists. In the general population, there is a widespread range in the prevalence of frailty ranging from 33 to $88 \%$ [39].

Nevertheless, there are several studies suggesting that frailty could be a strong risk factor for falling. In fact, Rossier et al. [18] reported a relationship between falls and malnutrition in CKD patients. Malnutrition is related to sarcopenia, which in turn is related to frailty [40] and deficiency in vitamin D, antioxidants and oligoelements as well as proteins associated with osteoporosis, disability and sarcopenia. Moreover, Li et al. [21] found suboptimal serum albumin levels as a risk factor for fall in CKD patients.

Serum 25-OH-D levels were related to falls [41] and death [42]. The 25-OH-D levels in CKD patients are generally lower than in the general population $[19,28]$. Boudville et al. [25] showed a relationship between suboptimal 25-OH-D levels and reduced quadricep muscle strength and consequently, an increased risk of falls. No relationship was detected with 1,25-OH-D levels demonstrating the greater influence of the active metabolite 25$\mathrm{OH}-\mathrm{D}$ on muscle strength versus $1,25-\mathrm{OH}-\mathrm{D}$. Rothenbacher et al. [19] analyzed a group of patients with CKD and suboptimal serum calcium levels. They found an 
inverse correlation between serum 25-OH-D and the risk of first fall. These data show that serum 25-OH-D levels, especially when serum calcium level are suboptimal, may be considered a risk factor for falling in CKD patients independent of the degree of renal dysfunction. This is mainly due to the loss of muscle strength.

The use of different tools or tests such as the inability to perform a 10-min walking test (walk for ten minutes without any help) to determine the risk of falls has been reported in the study of Desmet et al. [16]. Different studies $[11,12]$ analyzed the utility of the POMA test (Mobility Assessment-Performance Oriented) because it easily establishes balance and walking ability. Galvao et al. [28] evaluated the capacity of the POMA score to determine the risk of falling in CKD patients.

In community-dwelling older people, there is a strong association between the risk of falling and having had a previous fall. The association is even stronger when there is more than one previous fall [4]. Similar results have been found in CKD patients by Rossier et al. [18], Cook et al. [20] and Li et al. [21].

Two prospective cohort studies $[16,23]$ reported that multi-therapy including selective serotonin reuptake inhibitors are a risk factor for falls in CKD patients especially those over $60[29,43]$.

The relationship between diabetes mellitus and falling could be explained on the basis of its complications such as impaired vision due to retinopathy and peripheral neuropathy. In a cross-sectional study conducted in the general population, the risk of falls in patients with poorly controlled diabetes was high [44].

The majority of studies enrolled HD patients, and according to many authors, HD is a risk factor for falling because large amounts of intravascular volume are removed causing an electrolyte imbalance and post-dialysis hypotension. However, Roberts et al. [17] did not detect any relationship between changes in blood pressure before and after the HD session and falls. Moreover no relationship was found when patients were categorized by age-thus, patients over 70 might be particularly susceptible to changes in blood pressure.

\section{Consequences of falls}

The incidence of serious falls in CKD patients ranged between 0.20 and 0.37 falls/patient year. Abrasion, laceration and distortion were the most frequent consequences [20]; fractures ranged between $4 \%$ and $11.2 \%$ [20, 25]. Kutner et al. [25] underlined that patients who suffered severe fractures recovered their independence after the fall in $71 \%$ of cases. Moreover, Cook et al. [20] reported that $16 \%$ of falls required hospitalization, and $4 \%$ of falls caused the patient's death.

CKD patients have many complications due to falls $[7,30]$. One year after the fall, $25 \%$ of older people will die, $76 \%$ will have limited mobility, $50 \%$ will not be able to perform activities of daily living, and $22 \%$ would be admitted to a nursing home [29]. In addition to the physical consequences reported, Desmet et al. [16] stressed the importance of post-fall syndrome including fear of falling, which encourages the patient not to rely on walking. This causes a decrease in physical activity and creates a vicious cycle that further reduces physical activity and muscle mass.

\section{Limitations}

This review focused specifically on falls in CKD patients. On this premise, an electronic exhaustive search without language limitations was conducted. However, the number of selected studies was limited, and we cannot exclude the fact that this search method might not be fully comprehensive; however, relevant information has been extracted from the selected studies. We could not find a single randomized controlled study.

Although there is insufficient evidence to determine the methodological quality of the selected articles, we used the STROBE checklist to assess the reporting and the GRADE approach to assess the quality of evidence.

\section{Conclusions}

We concluded there are not many studies with high methodological quality despite their publication in peerreviewed journals. Thus, this review summarizes the current knowledge about falls in CKD patients.

To the best of our knowledge, data analyzing the impact of falls in CKD patients are scarce. The main result of this review is that falling is common in hemodialysis patients and nothing is currently known about falling in uraemic patients treated with transplantation or peritoneal dialysis or in subjects with pre-ESRD. This is a real problem for the health system because the number of elderly people with advanced renal failure is continuously increasing [28].

Given the multifactorial nature of falls, the identification of risk factors is essential for preventing such events. Frailty remains the most significant risk factor for falls, and its relevance is due to several factors including malnutrition, which is common in uremia. Malnutrition also causes disability and sarcopenia-factors that increase the risk of falling. Furthermore, the presence of CKD is associated with a decrease in the muscle strength in subjects who are elderly, have different comorbidities and/or need polypharmacy.

Despite the relevant information extracted here, more studies are needed especially randomized controlled studies to calculate precisely the incidence of falls in CKD population, the possible consequences of these falls, and a better definition of relevant risk factors. There should be a particular emphasis on frailty. Special 
attention must be placed on the elderly who are treated by HD-this appears to be a risk factor. Moreover a study should be designed to define if HD or peritoneal dialysis negatively impacts the risk of falls in older adults who need to start renal replacement therapy. This should address not only the underlying disease but also the effect of treatment. It might be worth also evaluating different risk factors for falls such as vision problems, substance abuse, and nocturia especially in pre-ESRD patients.

All of this information would provide further evidence to develop comprehensive and adjusted fall-prevention measures. This would reduce the economic and social burden for both families and health systems.

\section{Additional file}

Additional file 1: Checklist of items to include when reporting a systematic review (with or without meta-analysis) PRISMA 2009 Flow Diagram. (DOC $82 \mathrm{~kb}$ )

\section{Abbreviations \\ CKD: Chronic kidney disease; MeSH: Medical Subject Heading; PRISMA: Preferred Reporting Items for Systematic Reviews and Meta-Analyses; STROBE: Strengthening the Reporting of Observational; HD: Hemodialysis; 25-OH-D: 25-Hydroxy Vitamin D; POMA: Mobility Assessment-Performance Oriented.}

\section{Competing interests}

All authors declare that there are no actual or potential conflict of interest including any financial, personal or other relationships with other people or organizations that could inappropriately influence or be perceived to influence their work

\section{Authors' contributions}

PJL-S, ADG, ES, RT, MAR-B, RM, and FF participated in study's conception and design; FF, ADG, RT, AF, and CC handled the database, collected and analyzed the data, drafted the article, and interpreted the data. PJL-S, P MAR-B, RM and FF revised it critically for important intellectual content and gave final approval. All authors read and approved the final manuscript.

\section{Acknowledgements}

We would thank Donato Bragatto, Claudia Righini, and Manuela Zappaterra, from the Health Science Library of the Azienda Ospedaliera-Universitaria of Ferrara, for collecting unavailable bibliographic materials from external sources.

\section{Author details}

'Department of Nursing, The Maimonides Institute for Biomedical Research in Cordoba, University of Córdoba, University Hospital Reina Sofía of Córdoba, Córdoba, Spain. ${ }^{2}$ Clinica Medica, Department of Medical Science, University of Ferrara, Ferrara, Italy. ${ }^{3}$ Department of Medicine, Azienda Ospedaliero-Universitaria (AOU) of Ferrara, Ferrara, Italy. ${ }^{4}$ U.O. Formazione e Aggiornamento, Azienda Ospedaliero-Universitaria (AOU) of Ferrara, Ferrara, Italy

Received: 24 February 2015 Accepted: 19 October 2015

Published online: 29 October 2015

\section{References}

1. Plantinga LC. Socio-economic impact in CKD. Nephrol Ther. 2013:9:1-7.

2. Jha $V$, Wang $A Y$, Wang $H$. The impact of CKD identification in large countries: The burden of illness. Nephrol Dial Transplant. 2012;27 Suppl 3:iii32-8.
3. Deandrea S, Bravi F, Turati F, Lucenteforte E, La Vecchia C, Negri E. Risk factors for falls in older people in nursing homes and hospitals. A systematic review and meta-analysis. Arch Gerontol Geriatr. 2013;56:407-15.

4. Deandrea S, Lucenteforte E, Bravi F, Foschi R, La Vecchia C, Negri E. Risk factors for falls in community-dwelling older people: A systematic review and meta-analysis. Epidemiology. 2010;21:658-68.

5. Rubenstein LZ. Falls in older people: Epidemiology, risk factors and strategies for prevention. Age Ageing. 2006;35 Suppl 2:ii37-41.

6. World Health Organization. Ageing; Life Course Unit. WHO global report on falls prevention in older age. World Health Organization; 2008.

7. Zecevic AA, Salmoni AW, Speechley M, Vandervoort AA. Defining a fall and reasons for falling: Comparisons among the views of seniors, health care providers, and the research literature. Gerontologist. 2006;46:367-76.

8. Chang JT, Ganz DA. Quality indicators for falls and mobility problems in vulnerable elders. J Am Geriatr Soc. 2013;55 Suppl 2:S327-34.

9. Centers for Disease Control and Prevention (CDC). Fatalities and injuries from falls among older adults-United States, 1993-2003 and 2001-2005. MMWR Morb Mortal Wkly Rep. 2006;55:1221-4.

10. Khan K, Kunz R, Kleijnen J, Antes G. Systematic Reviews to Support Evidence-Based Medicine. 2nd ed. London: Hodder Arnold; 2011.

11. Moher D, Liberati A, Tetzlaff J, Altman DG. Preferred reporting items for systematic reviews and meta-analyses: The PRISMA statement. Ann Intern Med. 2009:151:364-8. w264.

12. von Elm E, Altman DG, Egger M, Pocock SJ, Gotzsche PC, Vandenbroucke JP. Strengthening the Reporting of Observational Studies in Epidemiology (STROBE) statement: Guidelines for reporting observational studies. BMJ. 2007;335:806-8

13. Jaeschke $R$, Guyatt $G H$, Dellinger $P$, Schünemann $H$, Levy MM, Kunz R, et al Use of GRADE grid to reach decisions on clinical practice guidelines when consensus is elusive. BMJ. 2008:31:337:a744.

14. Joanna Briggs Institute. Joanna Briggs Institute Reviewers'manual 2014 edition. 2014. Retrieved from http://joannabriggs.org/assets/docs/sumari/ ReviewersManual-2014.pdf [data access 24 November 2014]

15. Centre for Reviews and Dissemination, Systematic Reviews. CRD's Guidance for Undertaking Reviews in Health Care. York: University of York; 2008.

16. Desmet C, Beguin C, Swine C, Jadoul M, Université Catholique de Louvain Collaborative Group. Falls in hemodialysis patients: Prospective study of incidence, risk factors, and complications. Am J Kidney Dis. 2005:45:148-53.

17. Roberts R, Jeffrey C, Carlisle G, Brierley E. Prospective investigation of the incidence of falls, dizziness and syncope in haemodialysis patients. Int Urol Nephrol. 2007;39:275-9.

18. Rossier A, Pruijm M, Hannane D, Burnier M, Teta D. Incidence, complications and risk factors for severe falls in patients on maintenance haemodialysis. Nephrol Dial Transplant. 2012;27:352-7.

19. Rothenbacher D, Klenk J, Denkinger MD, Herbolsheimer F, Nikolaus T, Peter $R$, et al. Prospective evaluation of renal function, serum vitamin $D$ level, and risk of fall and fracture in community-dwelling elderly subjects. Osteoporos Int. 2014;25:923-32.

20. Cook WL, Tomlinson G, Donaldson M, Markowitz SN, Naglie G, Sobolev B, et al. Falls and fall-related injuries in older dialysis patients. Clin J Am Soc Nephrol. 2006:1:1197-204.

21. Li M, Tomlinson G, Naglie G, Cook WL, Jassal SV. Geriatric comorbidities, such as falls, confer an independent mortality risk to elderly dialysis patients. Nephrol Dial Transplant. 2008;23:1396-400.

22. Abdel-Rahman EM, Yan G, Turgut F, Balogun RA. Long-term morbidity and mortality related to falls in hemodialysis patients: Role of age and gender-a pilot study. Nephron Clin Pract. 2011;118:c278-84.

23. McAdams-DeMarco MA, Suresh S, Law A, Salter ML, Gimenez LF, Jaar BG, et al. Frailty and falls among adult patients undergoing chronic hemodialysis: A prospective cohort study. BMC Nephrol. 2013;16:14:224

24. Roberts RG, Kenny RA, Brierley EJ. Are elderly haemodialysis patients at risk of falls and postural hypotension? Int Urol Nephrol. 2003;35:415-21.

25. Kutner NG, Zhang R, Huang Y, Wasse H. Falls among hemodialysis patients: Potential opportunities for prevention? Clin Kidney J. 2014:7:257-63.

26. Cook WL, Jassal SV. Prevalence of falls among seniors maintained on hemodialysis. Int Urol Nephrol. 2005:37:649-52.

27. Boudville N, Inderjeeth C, Elder GJ, Glendenning P. Association between 25-hydroxyvitamin D, somatic muscle weakness and falls risk in end-stage renal failure. Clin Endocrinol (Oxf). 2010;73:299-304.

28. Galvao MH, Santos LIS, Barcelar JM, Marinho PEM. Assessment of the capacity of the Falls Efficacy Scale International in specifying the risk of 
falling in patients with chronic kidney disease on hemodialysis. Fisioter Pesqui. 2013;20:151-7.

29. Angalakuditi MV, Gomes J, Coley KC. Impact of drug use and comorbidities on in-hospital falls in patients with chronic kidney disease. Ann Pharmacother. 2007;41:1638-43.

30. Soriano TA, DeCherrie LV, Thomas DC. Falls in the community-dwelling older adult: A review for primary-care providers. Clin Interv Aging. 2007;2:545-54

31. Gama ZA, Gomez-Conesa A. Risk factors for falls in the elderly: Systematic review. Rev Saude Publica. 2008;42:946-56.

32. Dunlop DD, Manheim LM, Sohn MW, Liu X, Chang RW. Incidence of functional limitation in older adults: The impact of gender, race, and chronic conditions. Arch Phys Med Rehabil. 2002:83:964-71.

33. Lord SR, Sambrook PN, Gilber C, Kelly PJ, Nguyen T, Webster IW, et al. Postural stability, falls and fractures in the elderly: Results from the Dubbo Osteoporosis Epidemiology Study. Med J. 1994;160:684-5. 688-91.

34. Manolagas SC, Kousteni S, Jilka RL. Sex steroids and bone. Recent Prog Horm Res. 2002;57:385-409.

35. Gobbens RJ, van Assen MA, Luijkx KG, Schols JM. Testing an integral conceptual model of frailty. J Adv Nurs. 2012;68:2047-60.

36. Fried LP, Tangen CM, Walston J, Newman AB, Hirsch C, Gottdiener J, et al. Frailty in older adults: Evidence for a phenotype. J Gerontol A Biol Sci Med Sci. 2001;56:M146-56.

37. Rockwood K, Fox RA, Stolee P, Robertson D, Beattie BL. Frailty in elderly people: An evolving concept. CMAJ. 1994;150:489-95.

38. Bergman $\mathrm{H}$, Beland $\mathrm{F}$, Karunananthan $\mathrm{S}$, et al. Developpment d'un cadre de travail pour comprendre et etudier la frailite. Feronto et soc. 2004;109:15-29.

39. van lersel MB, Rikkert MG. Frailty criteria give heterogeneous results when applied in clinical practice. J Am Geriatr Soc. 2006;54:728-9.

40. Cederholm T, Nouvenne A, Ticinesi A, Maggio M, Lauretani F, Ceda GP, et al. The role of malnutrition in older persons with mobility limitations. Curr Pharm Des. 2014;20(19):3173-7.

41. Murad MH, Elamin KB, Abu Elnour NO, Elamin MB, Alkatib AA, Fatourech $M M$, et al. Clinical review: The effect of vitamin D on falls: a systematic review and meta-analysis. J Clin Endocrinol Metab. 2011:96:2997-3006.

42. Schöttker B, Ball D, Gellert C, Brenner H. Serum 25-hydroxyvitamin D levels and overall mortality. A systematic review and meta-analysis of prospective cohort studies. Ageing Res Rev. 2012;12:708-18.

43. Woolcott JC, Richardson KJ, Wiens MO, et al. Meta-analysis of the impact of 9 medication classes on falls in elderly persons. Arch Intern Med. 2009;169:1952-60

44. Tilling LM, Darawil K, Britton M. Falls as a complication of diabetes mellitus in older people. J Diabetes Complications. 2006;20:158-62.

\section{Submit your next manuscript to BioMed Central and take full advantage of:}

- Convenient online submission

- Thorough peer review

- No space constraints or color figure charges

- Immediate publication on acceptance

- Inclusion in PubMed, CAS, Scopus and Google Scholar

- Research which is freely available for redistribution 